\title{
Application of radiotherapy for hepatocellular carcinoma in current clinical practice guidelines
}

\author{
Chai Hong Rim, MD, Jinsil Seong, MD, PhD \\ Department of Radiation Oncology, Yonsei Cancer Center, Yonsei University College of Medicine, Seoul, Korea
}

In oncologic practice, treatment guidelines provide appropriate treatment strategies based on evidence. Currently, many guidelines are used, including those of the European Association for the Study of the Liver and European Organization for Research and Treatment of Cancer (EASL-EORTC), National Comprehensive Cancer Network (NCCN), Asia-Pacific Primary Liver Cancer Expert (APPLE), and Korean Liver Cancer Study Group and National Cancer Centre (KLCSG-NCC). Although radiotherapy is commonly used in clinical practice, some guidelines do not accept it as a standard treatment modality. In this review, we will investigate the clinical practice guidelines currently used, and discuss the application of radiotherapy.

Keywords: Radiotherapy, Hepatocellular carcinoma, Practice guideline

\section{Introduction}

Treatment guidelines are used in oncologic practice to provide the most appropriate therapeutic option(s) based on evidence. Currently, there are several guidelines for the treatment of hepatocellular carcinoma (HCC), including guidelines from the European Association for the Study of the Liver and European Organization for Research and Treatment of Cancer (EASLEORTC), which are based on the Barcelona Clinic Liver Cancer (BCLC) guidelines; the National Comprehensive Cancer Network (NCCN); Asia-Pacific Primary Liver Cancer Expert (APPLE); and the Korean Liver Cancer Study Group and National Cancer Centre (KLCSG-NCC).

The application of radiotherapy (RT) has increased over recent decades, as has the number of studies using the latest technologies, such as stereotactic body radiotherapy (SBRT) or proton therapy (Fig. 1). Many researchers have reported effective clinical outcomes for patients with HCC using RT [1-3]. However, RT is not a recommended option in the BCLC guidelines or in some of the international consensuses.

This review will investigate the utilization and perspectives of RT in the currently used treatment guidelines, examine the weaknesses of the guidelines and discuss about the application of RT.

\section{Evidence Grading Systems}

The clinical practice guidelines for HCC adopted different evidence grading systems. The EASL-EORTC guidelines used two systems: 1) the Physician Data Query (PDQ) Levels of Evidence for Adult and Pediatric Cancer Treatment Studies (evidence classification adapted from the National Cancer Institute) [4] and 2) the Grading of Recommendations, Assessment, Development and Evaluation (GRADE) [5,6]. The GRADE

Received 7 September 2016, Revised 19 September 2016, Accepted 20 September 2016.

Correspondence: Jinsil Seong, MD, PhD, Department of Radiation Oncology, Yonsei Cancer Center, Yonsei University College of Medicine, 50 Yonsei-ro, Seodaemun-gu, Seoul 03722, Korea. Tel: +82-2-2228-8111, Fax: +82-2-2227-7823, E-mail: jsseong@yuhs.ac

(C) This is an Open Access article distributed under the terms of the Creative Commons Attribution Non-Commercial License (http://creativecommons.org/ licenses/by-nc/4.0/) which permits unrestricted non-commercial use, distribution, and reproduction in any medium, provided the original work is properly cited.

www.e-roj.org 
A

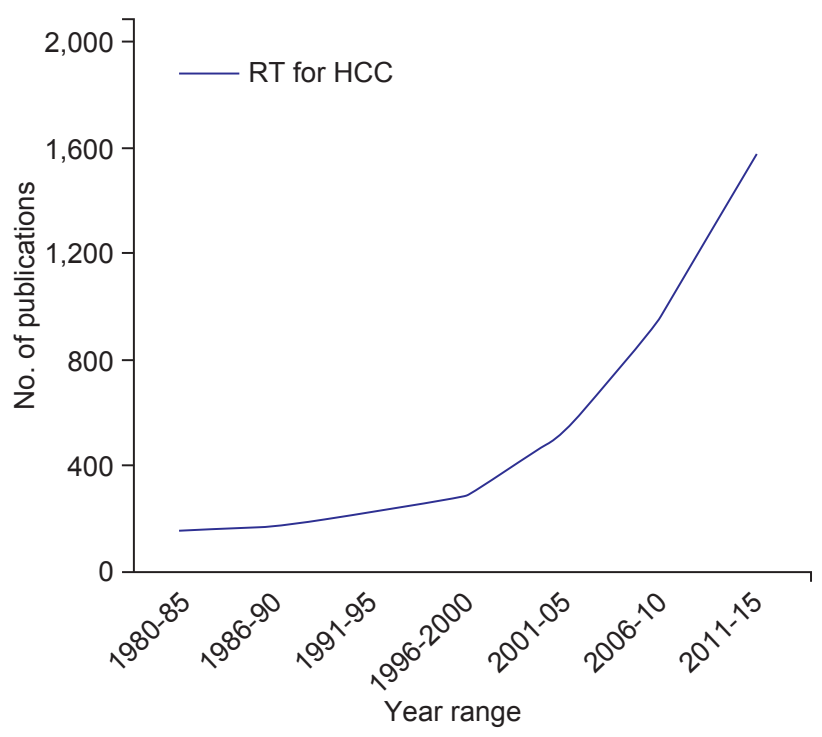

B

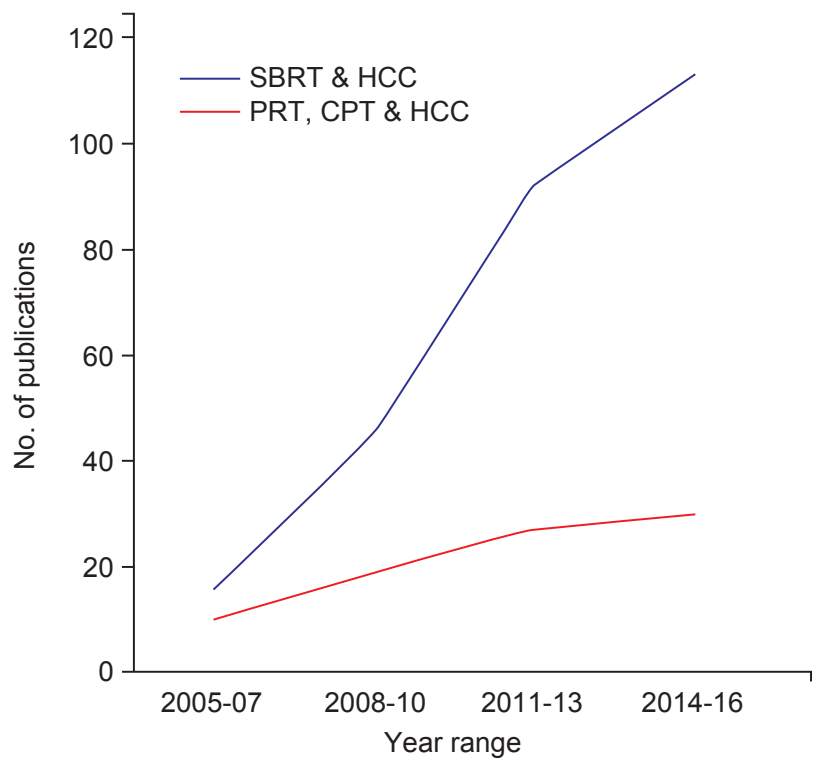

Fig. 1. Graphs of number of RT for HCC publications over time. Citation count based on searching Scopus database, limited to original articles only. (A) Blue line: search for ("radiation therapy" OR "radiotherapy") AND ("liver neoplasms" OR "hepatocellular carcinoma" OR "HCC"). (B) Blue line: search for ("SBRT" OR "SABR" OR "stereotactic body radiotherapy" OR "stereotactic ablative radiotherapy") AND ("liver neoplasms" OR "hepatocellular carcinoma" OR "HCC"). Red line: search for ("proton therapy" OR "charged particle") AND ("liver neoplasms" OR "hepatocellular carcinoma" OR "HCC"). RT, radiotherapy; HCC, hepatocellular carcinoma; SBRT, stereotactic body radiotherapy; SABR, stereotactic ablative radiotherapy; PRT, proton radiotherapy; CPT, charged particle therapy. system, which has been adopted by many key organizations, was also used in the APPLE consensus guidelines and the KLCSG-NCC guidelines. The NCCN Guidelines used their own system, the NCCN categories of Evidence and Consensus. This system considered characteristics unique to the oncologic field since high-quality evidence from large randomized controlled trials might not always exist, and in some situations treatment decisions should be made based on data from nonrandomized trials or multiple retrospective studies, or even on the experience of physicians [7].

\section{BCLC and EASL-EORTC Guidelines}

The BCLC staging system was established by the hepatologists' society, and it was first published in 1999 [8]. Numerous studies have been performed comparing the various $\mathrm{HCC}$ staging systems, and the BCLC staging system showed the best efficacy in many studies [9-11]. The BCLC staging system is widely used in the Asia-Pacific region; According to a report from the 2014 APPLE meeting, 24 of 33 institutions adopted the BCLC system as a staging modality [12]. In terms of treatment guidelines, the BCLC system has the advantage of recommending treatment options in accordance with stage, which is simple and easy to understand.

The BCLC staging and guidelines are most commonly used and are strongly recommended by the American Association for the Study of Liver Disease (AASLD) and the EASL. The AASLD guidelines state that the BCLC staging is the de facto staging system, which is widely accepted in practice and is used in many clinical trials [13]. EASL and EORTC published comprehensive clinical practice guidelines [14] in which BCLC staging is the sole recommended system; the use of other staging systems, even in combination with the BCLC system, is not recommended.

However, in the clinical guidelines of EASL-EORTC, the role of RT is seriously overlooked. The guidelines mention that the use of conventional external beam radiotherapy (EBRT) often causes radiation-induced liver disease (RILD) due to low radiation tolerance of cirrhotic liver, and the benefit of threedimensional conformal radiotherapy (3D-CRT) has only been proved in uncontrolled studies.

RT is ranked as the lowest for both the grade of recommendation and level of evidence in the guidelines. However, RT has been actively used in practice and its effectiveness has been proved in recent meta-analyses. Meng et al. [1] performed a meta-analysis comparing combined treatment of trans-arterial chemoembolization (TACE) plus RT 
versus TACE alone, and the combined treatment was associated with higher tumor response (odds ratio [OR], 3.14; 95\% confidence interval [Cl], 2.42 to 4.07) and better 2-year survival (OR, 2.39; 95\% Cl, 1.85 to 3.09). A more recent meta-analysis with a similar design confirmed the benefit of combinedtreatment RT in terms of 5-year survival $(\mathrm{OR}, 3.98 ; 95 \% \mathrm{Cl}, 1.89$ to 8.50$)$ and complete tumor response $(\mathrm{OR}, 2.73 ; 95 \% \mathrm{Cl}, 1.95$ to 3.81) [15].

The BCLC guidelines were last revised in 2011, and do not reflect subsequent clinical data or practice. The pioneering 3D-CRT studies were performed in the 1990s $[16,17]$, and newly developed technologies, such as intensity-modulated radiation therapy (IMRT), SBRT, and charged particle therapy (e.g., proton therapy), which can conformally deliver doses to HCC safely, are now commonly practiced. In the era of these advanced technologies, RILD due to whole liver irradiation is an outdated concern. A recent meta-analysis showed the pooled local control rates of SBRT and charged particle therapy to be $87 \%$ and $86 \%$, respectively, and the rates of acute hepatic toxicities of grade $>3$ to be $4.9 \%$ and $3.1 \%$, respectively [3].

In addition, BCLC guidelines suggest single treatment for each stage. However, it is difficult to perform the single standard treatment in practice because not all medical facilities can provide the best treatment, and patients can have various conditions in one stage. In addition, combined treatment is commonly performed in practice, where it has shown favorable clinical outcomes [18-21].

EASL-EORTC guidelines look down on RT, emphasizing the importance of evidence from randomized clinical trials. However, RT has commonly been performed for patients with advanced disease or who failed first-line treatments and were not good candidates for clinical trials. Furthermore, the research of radiation oncology has been performed without major support. In addition, HCC is more prevalent in developing countries, such as those in Asia and sub-Saharan Africa [22]. In those countries, the field of medical research is not developed enough. Therefore, the clinical experience of RT should not be disregarded. In addition, the suggestion of combined treatment or alternative options that can be applied more flexibly in clinical practice should be considered.

\section{The NCCN Guidelines}

The NCCN Guidelines are one of the most comprehensive and widely used oncologic standards. The guidelines are presented in a flow-chart format, suggesting treatments according to clinical presentation; this is understandable and practically useful for physicians. The guidelines are updated at least once a year to ensure that they take into account the most current evidence [23].

The 2015 update of the NCCN Guidelines ver. 2.0 considers locoregional therapies, including ablation, arterially directed therapies, and EBRT as preferred treatment options for inoperable patients or those with unresectable disease [24]. In the most recent NCCN Guidelines (version 2.2016), EBRT is suggested as a locoregional treatment option for patients with unresectable HCC who are ineligible for transplantation, who are inoperable owing to comorbidity, or who have local disease with/without minimal extrahepatic disease, with evidence level of $2 \mathrm{~B}$ (based on lower-level evidence, with consensus that the intervention is appropriate) [7]. For patients who are operable, locoregional therapy including EBRT is a treatment option, although resection is the preferred treatment [25].

The guidelines mention the feasibility of modern RT: EBRT allows focal high-dose irradiation to liver tumors, while sparing surrounding normal liver, thereby limiting the risk of RILD. Furthermore, EBRT can be applied irrespective of tumor location. The panels have considerable interests in SBRT. SBRT is suggested as an alternative for ablation and/or embolization techniques, or when they have failed or are contraindicated. The possible indications of SBRT are as follow: Tumors on the liver capsule which might be ruptured and cause track seeding with radiofrequency ablation (RFA) $[26,27]$; Lesions close to the major vessels where the effectiveness of ablation can be diminished due to the "heat sink effect" (cooling effect of blood flow) [28]; Lesions abutting the diaphragm which are at risk of diaphragmatic injury [29].

Consentient indications have not been confirmed, but SBRT is often performed on patients with 1-3 tumors and limited or no extrahepatic disease. Although SBRT is commonly applied for small tumors $(\leq 4-5 \mathrm{~cm})$, it may be used for larger lesions if sufficient uninvolved liver volume can be respected. SBRT is difficult to perform for lesions near the small bowel, owing to the risk of gastrointestinal toxicity [30].

The role of $\mathrm{RT}$ as a locoregional treatment for $\mathrm{HCC}$ is well documented in the NCCN Guidelines. Since the NCCN Guidelines are one of the most commonly and globally used oncologic guidelines, the guidelines may introduce the role of $\mathrm{RT}$ to the physicians of the oncologic society.

\section{The APPLE Consensus Guidelines}

The APPLE is an association of liver cancer experts in the Asia-Pacific region, and is the most active multi-national 
liver cancer association with International Liver Cancer Association (ILCA).The liver cancer specialists who participate in the APPLE include hepatologists, surgeons, radiologists, radiation oncologists, medical oncologists, and pathologists. At their meeting in 2014, the APPLE established comprehensive consensus guidelines for radiotherapy of HCC $[12,31]$. Specific recommendations for $\mathrm{RT}$ according to stage, based on the BCLC staging system, were proposed.

In the guidelines, techniques of modern EBRT, which might be unfamiliar for specialists other than radiation oncologists, are comprehensively explained. With the application of planning computed tomography (CT), 3D-CRT with dosevolume histogram (DVH) analysis has enabled accurate research on RILD [32]. With DVH analysis, physicians can understand the amount of irradiated dose quantitatively. IMRT enables more conformal and higher dose delivery, through the method of inverse planning: computerized planning with given dose prescriptions and limitations [33,34].

SBRT (or stereotactic ablative body RT [SABR]) is described as the accurate delivery of ablative radiation with a relatively large single dose in less than 5 fractions. This treatment has attracted interest owing to excellent local control, short treatment time, and feasibility of use regardless of location. The number of registered prospective SBRT (or SABR) protocols has dramatically increased on the clinicaltrials.gov [35].

Proton therapy has an advantage in terms of dose distribution, with its characteristics of Bragg peak: a proton beam can confer a minimal dose to the front of the tumor, maximal dose at the tumor, and almost no dose behind the tumor [36]. Proton therapy showed excellent local control and survival in patients with HCC $[37,38]$. Hata et al. [39] performed proton therapy for 19 HCC patients with ChildPugh class $C$, who would have received supportive treatment according to the BCLC guidelines. Proton therapy showed favorable outcomes, with a 1-year overall survival rate of $53 \%$ and a progression-free survival rate of $47 \%$.

Combination treatment with RT has been actively studied. TACE and hepatic arterial infusion chemotherapy (HAIC) have been used as combination agents to enhance the effect of RT and clinical outcomes $[19,20]$. Combination use of RT and a targeted agent, such as sorafenib, might have a synergistic effect, decreasing intrahepatic progression [18].

Taken together, the APPLE consensus guidelines may help liver specialists, not only radiation oncologists, to understand the applications and techniques of RT. In addition, the APPLE consensus guidelines were to widen application of RT for HCC by proposing the indications of RT across all the stages.

\section{KLCSG-NCC Korea Guidelines}

KLCSG and NCC Korea had published first practice guidelines at 2003, and recently updated at 2014. The KLCSG-NCC aimed to suggest comprehensive guidelines, considering specific clinical conditions in Asia, which can differ from those in Western countries [40]. The modified Union for International Cancer Control (mUICC) staging system was adopted to develop the KLCSG-NCC guidelines.

The mUICC staging system is based on a tumor-nodemetastasis (TNM) system, which is most widely used across all solid tumors [41]. It helps unification of clinical data since the mUICC system was adopted from the first version of KLCSG-NCC guidelines. The BCLC staging system recommends treatment according to stage, and has been validated in many studies. It is supported by EASL and AASLD $[13,14]$; hence, it can be useful for international exchange of information. However, BCLC categorizes Child-Pugh class A and B patients into one stage, whereas the liver function of patients in these classes can vary widely. Moreover, the recommended treatments are too simple, and may not fit with clinical practice [40].

The KLCSG-NCC guidelines provide multiple treatment suggestions for each stage, and state the best and the alternative options. Proposal of multiple treatments and alternative options is a reasonable concept considering the individual circumstances of patients and the difference between medical facilities.

According to the guidelines, RT is an alternative option for mUICC stage I patients who are not candidates for resection or RFA. For a stage II single tumor $>2 \mathrm{~cm}$ without vascular invasion, RT is also an alternative option. RT is recommended as one of the best options for a stage II single tumor $\leq 2 \mathrm{~cm}$ with vascular invasion, and a stage III single tumor $>2 \mathrm{~cm}$ with vascular invasion. For stage IV patients with lymph node or extrahepatic metastases, RT is suggested as an alternative, while sorafenib is recommended as the best option.

EBRT is usually performed for patients with Child-Pugh class A or favorable class B [42]. RT should be performed with CT-based planning, and V30 (volume irradiated $\geq 30$ Gy) should be less than $60 \%$ of the liver volume. For hypofractionated RT with fewer than 10 fractions, the volume of normal liver irradiated $<15 \mathrm{~Gy}$ should exceed $700 \mathrm{~mL}$, and the mean dose for normal liver should be limited to $<28 \mathrm{~Gy}$ (the dose should be evaluated in EQD2; equivalent dose for 2 Gy per fraction treatment) $[32,43,44]$.

EBRT is recommended for incompletely treated HCC after 
Table 1. Comparison of currently used guidelines

\begin{tabular}{|c|c|c|c|c|}
\hline Guidelines & Staging system & Evidence stratification & RT recommendation & Contents of RT \\
\hline EASL-EORTC & $\mathrm{BCLC}$ & $\begin{array}{l}\text { GRADE }[5,6] \\
\text { PDQ level of evidence }[4]\end{array}$ & - & None \\
\hline NCCN & $\begin{array}{l}\text { Child-Pugh class } \\
\text { UNOS criteria }\end{array}$ & $\begin{array}{l}\text { NCCN Level of Evidence and } \\
\text { Consensus [7] }\end{array}$ & $+1-$ & General indications \\
\hline APPLE & $\mathrm{BCLC}$ & GRADE & ++ & $\begin{array}{l}\text { Indications according to stage } \\
\text { Specific RT techniques }\end{array}$ \\
\hline KLSCG-NCC & mUICC & GRADE & + & $\begin{array}{l}\text { Indications according to stage as } \\
\text { either one of the best or alternative } \\
\text { selections }\end{array}$ \\
\hline
\end{tabular}

RT, radiotherapy; EASL, European Association for the Study of the Liver; EORTC, European Organization for Research and Treatment of Cancer; BCLC, Barcelona Clinic Liver Cancer; GRADE, Grading of Recommendations, Assessment, Development and Evaluation; PDO, Physician Data Query; NCCN, National Comprehensive Cancer Network; UNOS, United Network for Organ Sharing; APPLE, Asia-Pacific Primary liver Cancer Expert Meeting; KLSCG, Korean Liver Cancer Study Group; NCC, National Cancer Center; mUICC, modified Union for International Cancer Control.

Table 2. Clinical example of treatment applications according to practice guidelines for HCC

\begin{tabular}{|c|c|c|c|c|c|}
\hline & Guidelines & $\mathrm{BCLC}$ & NCCN & APPLE & KLSCG-NCC ${ }^{a)}$ \\
\hline \multirow[t]{3}{*}{ Single, $>2 \mathrm{~cm}$, without $\mathrm{Vl}$} & Classification & Early (A) & $\begin{array}{l}\text { Resectable or } \\
\text { transplantable }\end{array}$ & Early (A) & mUICC II \\
\hline & $\begin{array}{l}\text { Primary or } \\
\text { preferred option }\end{array}$ & LT or RFA/PEI & Resection or LT & LT or RFA/PEI & Resection, RFA \\
\hline & Alternative option & $(-)$ & $\begin{array}{l}\text { Locoregional } \\
\text { treatment }\end{array}$ & $\begin{array}{l}\text { SABR } \\
\text { Hypofractionated RT }\end{array}$ & TACE, LT, EBRT \\
\hline \multirow[t]{3}{*}{ Single, $\leq 2 \mathrm{~cm}$, with VI } & Classification & Advanced $(\mathrm{C})$ & Unresectable $^{b)}$ & Advanced & mUICC II \\
\hline & $\begin{array}{l}\text { Primary or } \\
\text { preferred option }\end{array}$ & Sorafenib & $\begin{array}{l}\text { Locoregional treatment } \\
\text { (ablation, arterial } \\
\text { directed therapies, } \\
\text { EBRT) }\end{array}$ & Sorafenib & $\begin{array}{l}\text { TACE, EBRT, } \\
\text { sorafenib }\end{array}$ \\
\hline & Alternative option & $(-)$ & $\begin{array}{l}\text { Systemic treatment } \\
\text { Supportive care }\end{array}$ & Combined RT & Resection \\
\hline \multirow[t]{3}{*}{ Single, $>2 \mathrm{~cm}$, with Vl } & Classification & Advanced (C) & Unresectable $^{b)}$ & Advanced & mUICC III \\
\hline & $\begin{array}{l}\text { Primary or } \\
\text { preferred option }\end{array}$ & Sorafenib & $\begin{array}{l}\text { Locoregional treatment } \\
\text { (ablation, arterial } \\
\text { directed therapies, } \\
\text { EBRT) }\end{array}$ & Sorafenib & $\begin{array}{l}\text { TACE, EBRT, } \\
\text { sorafenib }\end{array}$ \\
\hline & Alternative option & $(-)$ & $\begin{array}{l}\text { Systemic treatment } \\
\text { Supportive care }\end{array}$ & Combined RT & Resection \\
\hline
\end{tabular}

HCC, hepatocellular carcinoma; BCLC, Barcelona Clinic Liver Cancer; NCCN, National Comprehensive Cancer Network; APPLE, Asia-Pacific Primary Liver Cancer Expert Meeting; KLSCG-NCC, Korean Liver Cancer Study Group and National Cancer Centre; mUICC, modified Union for International Cancer Control; LT, liver transplantation; RFA, radiofrequency ablation; PEI, percutaneous ethanol injection; VI, vascular invasion; SABR, stereotactic ablative radiotherapy; RT, radiotherapy; TACE, trans-arterial chemoembolization; EBRT, external beam radiotherapy. a) KLSCG-NCC guidelines are intended for patients with Child-Pugh class A, no portal hypertension, and Eastern Cooperative Oncology Group (ECOG) performance status 0-1.

${ }^{b)}$ Hepatic resection for tumors with vascular invasion is controversial. 
Table 3. Phase 3 randomized clinical trials investigating role of radiotherapy in hepatocellular carcinoma

\begin{tabular}{|c|c|c|c|c|c|}
\hline NCT no. & $\begin{array}{l}\text { Estimated } \\
\text { enrollment }\end{array}$ & Arms & $\begin{array}{c}\text { Primary outcome } \\
\text { measures }\end{array}$ & $\begin{array}{l}\text { Secondary or other } \\
\text { outcome measures }\end{array}$ & $\begin{array}{l}\text { Estimated primary } \\
\text { completion date }\end{array}$ \\
\hline NCT02794337 & 386 & $\begin{array}{l}\text { Arm 1: DEB TACE } \\
\text { Arm 2: DEB TACE \& SBRT }\end{array}$ & In-field PFS & $\begin{array}{l}\text { CSS, tumor response, } \\
\text { QoL, toxicity }\end{array}$ & Jan 2019 \\
\hline NCT01963429 & 144 & $\begin{array}{l}\text { Arm 1: RFA } \\
\text { Arm 2: Proton beam therapy }\end{array}$ & local PFS & DFS, OS & Dec 2018 \\
\hline NCT01730937 & 368 & $\begin{array}{l}\text { Arm 1: Sorafenib tosylate } \\
\text { Arm 2: SBRT and sorafenib } \\
\text { tosylate }\end{array}$ & OS & $\begin{array}{l}\text { TTP, PFS, toxicity, QoL, } \\
\text { quality adjusted } \\
\text { survival }\end{array}$ & Jun 2016 \\
\hline NCT02762266 & 160 & $\begin{array}{l}\text { Arm 1: TACE } \\
\text { Arm 2: SBRT }\end{array}$ & FFLP & PFS, OS & - \\
\hline NCT02511522 & 60 & $\begin{array}{l}\text { Arm 1: Best supportive care } \\
\text { Arm 2: Best supportive care } \\
\text { \& RT }\end{array}$ & $\begin{array}{l}\text { Improvement of } \\
\text { pain/discomfort }\end{array}$ & $\begin{array}{l}\text { Adverse event, 90-day } \\
\text { survival, QoL, reduction } \\
\text { of opioid use }\end{array}$ & Jul 2018 \\
\hline NCT02323360 & 80 & $\begin{array}{l}\text { Arm 1: SBRT } \\
\text { Arm 2: TACE }\end{array}$ & Local control & PFS, OS, toxicity & Nov 2016 \\
\hline NCT02125396 & 150 & $\begin{array}{l}\text { Arm 1: RT } \\
\text { Arm 2: TACE }\end{array}$ & OS & Recurrence rate & Dec 2017 \\
\hline
\end{tabular}

DEB, drug eluting bead; TACE, trans-arterial chemoembolization; SBRT, stereotactic body radiotherapy; PFS, progression free survival; CSS, cause specific survival; QoL, quality of life; RFA, radiofrequency ablation; DFS, disease free survival; OS, overall survival; TTP, time to progression; FFLP, freedom from local progression; RT, radiotherapy.

TACE, with evidence level B2 (moderate quality of evidence with weak strength of recommendation) [1]. A tumor with portal vein invasion is also an indication, with evidence level C1 (low quality of evidence with strong recommendation) $[2,20]$. EBRT is an effective treatment for palliation of pain, which is caused by the tumor itself or bone metastases, and symptoms of brain, lungs, and lymph nodes metastases [4548]. Treatment with EBRT is expected to confer a survival benefit and palliation effect for patients with jaundice due to biliary obstruction [49]. Palliative RT is recommended with evidence level B1 (moderate quality of evidence with strong recommendation).

The KLCSG guidelines provide comprehensive information across various clinical fields, including diagnosis, treatment, surveillance, and prevention. They propose practical and evidence-based indications for RT in variable clinical situations, using an anatomically based staging system. Also, the guidelines provide comprehensive implementation of RT which is clinically helpful.

\section{Conclusion}

Comparison of the currently used guidelines is summarized in Table 1 [4-7]. Although RT is a frequently used treatment option for HCC, the applications of RT differ according to the guidelines. Applications of treatment, with clinical examples according to the guidelines, are shown in Table 2. Some guidelines, especially those of the EASL-EORTC, are negative about the application of RT, asserting the importance of evidence from randomized clinical trials. There are several ongoing randomized trials, which are expected to prove the efficacy of RT in the near future (Table 3). In addition, the clinical experiences of RT should not be neglected. RT has been commonly performed for patients who were hard to cure, and research has been performed without major support. We expect the globally accepted guidelines reflecting clinical practice, as well as adopting multimodal treatment.

\section{Conflict of Interest}

No potential conflict of interest relevant to this article was reported.

\section{Acknowledgments}

This study was supported by a grant of the Korean Health Technology R\&D Project (A121982), Ministry of Health \& Welfare, Republic of Korea. 


\section{References}

1. Meng MB, Cui $Y L, L u Y$, et al. Transcatheter arterial chemoembolization in combination with radiotherapy for unresectable hepatocellular carcinoma: a systematic review and meta-analysis. Radiother Oncol 2009;92:184-94.

2. Im JH, Yoon SM, Park HC, et al. Radiotherapeutic strategies for hepatocellular carcinoma with portal vein tumour thrombosis in a hepatitis B endemic area. Liver Int 2016 Jun 18 [Epub]. http://dx.doi.org/10.1111/liv.13191.

3. Oi WX, Fu S, Zhang O, Guo XM. Charged particle therapy versus photon therapy for patients with hepatocellular carcinoma: a systematic review and meta-analysis. Radiother Oncol 2015;114:289-95.

4. National Cancer Institute. Levels of evidence for adult and pediatric cancer treatment studies (PDO) [Internet]. Bethesda, MD: National Cancer Institute; c2015 [cited 2016 Aug 17]. Available from: https://www.cancer.gov/publications/pdq/ levels-evidence/treatment.

5. Andrews J, Guyatt G, Oxman AD, et al. GRADE guidelines: 14 . going from evidence to recommendations: the significance and presentation of recommendations. J Clin Epidemiol 2013;66:719-25.

6. Guyatt $G H, O x m a n A D$, Kunz $R$, et al. Going from evidence to recommendations. BMJ 2008;336:1049-51.

7. National Comprehensive Cancer Network. NCCN categories of evidence and consensus. [Internet]. Fort Washington, PA: National Comprehensive Cancer Network; c2016 [cited 2016 Aug 17]. Available from: https://www.nccn.org/professionals/ physician_gls/categories_of_consensus.asp.

8. Llovet JM, Bru C, Bruix J. Prognosis of hepatocellular carcinoma: the BCLC staging classification. Semin Liver Dis 1999;19:329-38.

9. Marrero JA, Fontana RJ, Barrat $A$, et al. Prognosis of hepatocellular carcinoma: comparison of 7 staging systems in an American cohort. Hepatology 2005;41:707-16.

10. Cillo $U$, Bassanello $M$, Vitale $A$, et al. The critical issue of hepatocellular carcinoma prognostic classification: which is the best tool available? J Hepatol 2004;40:124-31.

11. Gomaa Al, Hashim MS, Waked I. Comparing staging systems for predicting prognosis and survival in patients with hepatocellular carcinoma in Egypt. PLoS One 2014;9:e90929.

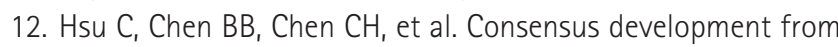
the 5th Asia-Pacific Primary Liver Cancer Expert Meeting (APPLE 2014). Liver Cancer 2015;4:96-105.

13. Bruix J, Sherman M; American Association for the Study of Liver Diseases. Management of hepatocellular carcinoma: an update. Hepatology 2011;53:1020-2.

14. European Association for the Study of the Liver; European Organisation for Research and Treatment of Cancer. EASL-EORTC clinical practice guidelines: management of hepatocellular carcinoma. J Hepatol 2012;56:908-43.

15. Huo $\mathrm{TI}$, Huang $Y H$, Lee SD, Wu JC. Is there an ideal prognostic model for hepatocellular carcinoma? Gut 2005;54:1348.

16. Dawson LA, McGinn CJ, Normolle D, et al. Escalated focal liver radiation and concurrent hepatic artery fluorodeoxyuridine for unresectable intrahepatic malignancies. J Clin Oncol 2000;18:2210-8.

17. Seong J, Park HC, Han KH, Chon CY. Clinical results and prognostic factors in radiotherapy for unresectable hepatocellular carcinoma: a retrospective study of 158 patients. Int J Radiat Oncol Biol Phys 2003;55:329-36.

18. Chen SW, Lin LC, Kuo YC, Liang JA, Kuo CC, Chiou JF. Phase 2 study of combined sorafenib and radiation therapy in patients with advanced hepatocellular carcinoma. Int J Radiat Oncol Biol Phys 2014;88:1041-7.

19. Han KH, Seong J, Kim JK, Ahn SH, Lee DY, Chon CY. Pilot clinical trial of localized concurrent chemoradiation therapy for locally advanced hepatocellular carcinoma with portal vein thrombosis. Cancer 2008;113:995-1003.

20. Yoon SM, Lim YS, Won HJ, et al. Radiotherapy plus transarterial chemoembolization for hepatocellular carcinoma invading the portal vein: long-term patient outcomes. Int J Radiat Oncol Biol Phys 2012;82:2004-11.

21. Kim SW, Oh D, Park HC, et al. Transcatheter arterial chemoembolization and radiation therapy for treatment-naive patients with locally advanced hepatocellular carcinoma. Radiat Oncol J 2014;32:14-22.

22. Torre LA, Bray F, Siegel RL, Ferlay J, Lortet-Tieulent J, Jemal $A$ Global cancer statistics, 2012. CA Cancer J Clin 2015;65:87108.

23. National Comprehensive Cancer Network [Internet]. Fort Washington, PA: National Comprehensive Cancer Network c2016 [cited 2016 Aug 17]. Available from: https://www.nccn. org.

24. National Comprehensive Cancer Network. NCCN clinica practice guidelines in oncology, hepatobiliary cancers 2015 Fort Washington, PA: National Comprehensive Cancer Network; c2016.

25. National Comprehensive Cancer Network. NCCN clinical practice guidelines in oncology, hepatobiliary cancers 2016 2 [Internet]. Fort Washington, PA: National Comprehensive Cancer Network; c2016 [cited 2016 Aug 17]. Available from: http://www.nccn.org/professionals/physician_gls/f_guidelines. asp.

26. Lencioni $R$, Cioni D, Crocetti L, et al. Early-stage hepatocellular carcinoma in patients with cirrhosis: long-term results of percutaneous image-guided radiofrequency ablation. Radiology 2005;234:961-7.

27. Llovet JM, Vilana $R, B r u C$, et al. Increased risk of tumor seeding after percutaneous radiofrequency ablation for single hepatocellular carcinoma. Hepatology 2001;33:1124-9. 
28. Pillai K, Akhter J, Chua TC, et al. Heat sink effect on tumor ablation characteristics as observed in monopolar radiofrequency, bipolar radiofrequency, and microwave, using ex vivo calf liver model. Medicine (Baltimore) 2015;94:e580.

29. Head HW, Dodd GD 3rd, Dalrymple NC, et al. Percutaneous radiofrequency ablation of hepatic tumors against the diaphragm: frequency of diaphragmatic injury. Radiology 2007;243:877-84.

30. Sanuki N, Takeda A, Kunieda E. Role of stereotactic body radiation therapy for hepatocellular carcinoma. World J Gastroenterol 2014;20:3100-11.

31. Park HC, Yu Jl, Cheng JC, et al. Consensus for radiotherapy in hepatocellular carcinoma from the 5th Asia-Pacific Primary Liver Cancer Expert Meeting (APPLE 2014): current practice and future clinical trials. Liver Cancer 2016;5:162-74.

32. Kim TH, Kim DY, Park JW, et al. Dose-volumetric parameters predicting radiation-induced hepatic toxicity in unresectable hepatocellular carcinoma patients treated with threedimensional conformal radiotherapy. Int J Radiat Oncol Biol Phys 2007;67:225-31.

33. Cheng JC, Wu JK, Huang CM, et al. Dosimetric analysis and comparison of three-dimensional conformal radiotherapy and intensity-modulated radiation therapy for patients with hepatocellular carcinoma and radiation-induced liver disease. Int J Radiat Oncol Biol Phys 2003;56:229-34.

34. Hamacher HW, Kufer KH. Inverse radiation therapy planning: a multiple objective optimization approach. Discrete Appl Math 2002;118:145-61.

35. ClinicalTrials.gov [Internet]. Bethesda, MD: ClinicalTrials. gov; c2016 [cited 2016 Aug 17]. Available from: https:// clinicaltrials.gov/.

36. DeLaney TF. Proton therapy in the clinic. Front Radiat Ther Oncol 2011:43:465-85.

37. Bush DA, Hillebrand DJ, Slater JM, Slater JD. High-dose proton beam radiotherapy of hepatocellular carcinoma: preliminary results of a phase II trial. Gastroenterology 2004;127(5 Suppl 1):S189-93.

38. Nakayama $H$, Sugahara $S$, Tokita $M$, et al. Proton beam therapy for hepatocellular carcinoma: the University of Tsukuba experience. Cancer 2009;115:5499-506.

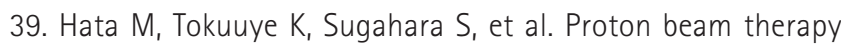
for hepatocellular carcinoma patients with severe cirrhosis. Strahlenther Onkol 2006;182:713-20.

40. Korean Liver Cancer Study Group (KLCSG); National Cancer Center, Korea (NCC). 2014 Korean Liver Cancer Study GroupNational Cancer Center Korea practice guideline for the management of hepatocellular carcinoma. Korean J Radiol 2015;16:465-522.

41. Union for International Cancer Control (UICC). UICC staging system [Internet]. Geneva: Union for International Cancer Control (UICC); c2016 [cited 2016 Aug 17]. Available from: http://www.uicc.org.

42. Hawkins MA, Dawson LA. Radiation therapy for hepatocellular carcinoma: from palliation to cure. Cancer 2006;106:1653-63.

43. Schefter $T E$, Kavanagh BD, Timmerman RD, Cardenes HR Baron A, Gaspar LE. A phase I trial of stereotactic body radiation therapy (SBRT) for liver metastases. Int J Radiat Oncol Biol Phys 2005;62:1371-8.

44. Pan CC, Kavanagh BD, Dawson LA, et al. Radiationassociated liver injury. Int J Radiat Oncol Biol Phys 2010;76(3 Suppl):S94-100.

45. Choi HJ, Cho BC, Sohn JH, et al. Brain metastases from hepatocellular carcinoma: prognostic factors and outcome: brain metastasis from HCC. J Neurooncol 2009;91:307-13.

46. He J, Zeng ZC, Tang ZY, et al. Clinical features and prognostic factors in patients with bone metastases from hepatocellular carcinoma receiving external beam radiotherapy. Cancer 2009;115:2710-20.

47. Jiang W, Zeng ZC, Zhang JY, Fan J, Zeng MS, Zhou J. Palliative radiation therapy for pulmonary metastases from hepatocellular carcinoma. Clin Exp Metastasis 2012;29:197205.

48. Yoon SM, Kim JH, Choi EK, et al. Radioresponse of hepatocellular carcinoma-treatment of Iymph node metastasis. Cancer Res Treat 2004;36:79-84.

49. Huang JF, Wang LY, Lin ZY, et al. Incidence and clinical outcome of icteric type hepatocellular carcinoma. J Gastroenterol Hepatol 2002;17:190-5. 